\title{
Por uma análise dialógica do gênero anúncio publicitário
}

\author{
For a Dialogical Analysis of the Gender Advertising
}

Fernanda Fernandes Pimenta de Almeida Lima ${ }^{1}$, Warley Soares Miranda ${ }^{2}$

Resumo: O presente trabalho, realizado à luz dos estudos bakhtinianos dos gêneros discursivos, busca investigar o dialogismo presente em um anúncio publicitário da década de 1970. No devido anúncio, observamos como os sentidos remissivos a uma identidade da mulher materializam-se em enunciados motivadores de seu histórico silenciamento na sociedade. Uma vez que os enunciados não existem fora das relações dialógicas, neste artigo, discutimos a noção de gêneros em uma perspectiva discursiva, portanto valemo-nos teoricamente de autores, como Bakhtin (2003), Gregolin (2007a, 2007b), Orlandi (2003), entre outros. Tal pesquisa, de base empírica e documental, propõe-se a interpretar um anúncio publicitário, observando como a alteridade se inscreve em sua materialidade e como o seu caráter heterogêneo demarca sentidos que podem ser explorados em sua configuração enunciativa e no contexto histórico em que se apresenta. Sabemos que o discurso, por incorporar o discurso alheio, possibilita reflexões que suplantam não apenas os sentidos sobre o lugar da mulher na sociedade, mas, principalmente, questões que podem ser atreladas às diferentes reflexões em sala de aula e à construção do conhecimento crítico.

Palavras-chave: Dialogismo; Gêneros do Discurso; Anúncio Publicitário; Mulher.

Abstract: This work, carried out in the light of Bakhtinian studies of the discursive genres, seeks to investigate the dialogism present in a 1970s advertisement. In the due advertisement, we observe how the remissive senses to a woman's identity materialize in motivating statements of her historical silence in society. Since the enunciations do not exist outside the dialogic relations, in this article we discuss the notion of genders in a discursive perspective, so we theoretically use authors like Bakhtin (2003), Gregolin (2007a, 2007b), Orlandi (2003), among others. This research, based on empirical and documentary research, proposes to interpret an advertisement, observing how otherness is inscribed in its materiality and how its heterogeneous character demarcates meanings that can be explored in its enunciative configuration and in the historical context in which it is presented. We know that discourse, by incorporating the discourse of others, enables reflections that supplant not only the senses about the place of women in society, but mainly questions that can be tied to different reflections in the classroom and the construction of critical knowledge.

Keywords: Dialogism; Genres of Discourse; Advertising; Women.

\section{Introdução}

\footnotetext{
${ }^{1}$ Professora do Departamento de Letras do Instituto Acadêmico de Licenciaturas (IAEL) da Universidade Estadual de Goiás (UEG).

${ }^{2}$ Discente do Curso de Pós-Graduação em Linguagem, Cultura e Ensino, da Universidade Estadual de Goiás (UEG/Campus Metropolitano).
} 
Perscrutar os enunciados constitutivos de anúncios publicitários necessariamente é uma ação que dialoga constantemente com as práticas sociais na atualidade e em épocas remotas. Nesta perspectiva, este artigo visa analisar o processo de investigação dialógica fundamentado em Mikhail Bakhtin (2003), tendo como objeto de análise um anúncio publicitário da década de 1970 que dá a problematizar questões remissivas à identidade da mulher na sociedade da época. As análises, realizadas à luz da teoria bakhtiniana dos Gêneros do Discurso, buscam intercalar um diálogo com os estudos discursivos, visando a problematizações que permeiam as práticas sociais e a sua premente relação com as questões relacionadas às identidades femininas e ao seu papel na sociedade.

Discutir anúncios publicitários não é absolutamente novidade, ainda mais quando estes remetem à temática do papel social da mulher. Entretanto, é um tema que não se esgota pela sua incessante relação com as práticas da atualidade. Os enunciados constitutivos dos anúncios publicitários produzem a estrutura de um dizer sempre pertencente a uma dada ordem de discursos e emergem de condições de produção ideologicamente marcadas.

Neste sentido, esta reflexão tem o papel de refazer leituras de uma atualidade que insiste em reatualizar histórias de tempos pretéritos. Buscamos, para tanto, estruturar tal investigação nas seguintes partes: inicialmente, discutimos a noção de gêneros do discurso em uma perspectiva bakhtiniana, especificamente, em sua esteira, perscrutamos a noção de anúncio publicitário. Em seguida, apresentamos um conciso apanhado sobre a noção de dialogismo em sua irrestrita relação com a heterogeneidade da linguagem. Por fim, analisamos o anúncio publicitário coletado, intercalando um diálogo com os sentidos que identificam um lugar para a mulher na sociedade.

\section{Os gêneros do discurso: relevância teórica}

Bakhtin (2003) aborda a linguagem em duas dimensões adjacentes, entre elas, a relação entre a atividade humana e o uso da língua. O teórico reforça que o uso da língua se efetua por meio de formas de enunciados que podem ser orais ou escritos. Assim, a atividade humana mobiliza enunciados que se interdependem.

Consoante Bakhtin (2003, p. 262), 
[...] todas as esferas da atividade humana, por mais variadas que sejam, estão sempre relacionadas com a utilização da língua. Não é de surpreender que o caráter e os modos dessa utilização sejam tão variados como as próprias esferas da atividade humana, o que não contradiz a unidade nacional de uma língua. A utilização da língua efetua-se em forma de enunciados (orais e escritos), concretos e únicos, que emanam dos integrantes duma ou doutra esfera da atividade humana.

Assim, para o autor, formam-se padrões típicos de atividades humanas, cujas ações são dinâmicas e mutáveis. Os enunciados acompanham essas ações, materializando-as em linguagem, dando-lhes sentido, em sua relativa estabilidade de formas nas diferentes esferas sociais em que se realizam. Situar os gêneros segundo as práticas que os mobilizam é também pensar as condições que situam os sujeitos em sociedade, sua interação para com o outro, suas ações, suas escolhas e, necessariamente, os enunciados que os identificam. Advém também daí a relevância de se estudarem de modo profícuo os gêneros discursivos em sala de aula.

Trabalhar com os gêneros do discurso em sala de aula possibilita a inclusão do leitor no processo de interpretação dos sentidos. Embora necessária, e de suma pertinência, essa não é uma tarefa fácil de se realizar. Ao mesmo tempo em que revela a estrutura dialogal do gênero, ela estimula, entre os leitores, o debate e os seus posicionamentos divergentes, possibilitando mostrar-lhes um amplo e complexo espectro de opiniões, equivocadas ou acertadas, sobre as práticas sociais que movem os sujeitos. Com isso, trabalhar os gêneros em seus aspectos estruturais e dialogal é convocar de seu leitor uma postura interpretativa, um olhar que se movimenta entre a composição do gênero e as esferas sociais que lhe dão existência, que elaboram suas formas e que movem seus sentidos.

Bakhtin (2003, p. 262-263), em sua clássica definição de gêneros do discurso, observa como estes encontram respaldo fundamentado no diálogo com as ações de comunicação e interação que mobilizam os sujeitos em sociedade.

Qualquer enunciado considerado isoladamente é, claro, individual, mas cada esfera de utilização da língua elabora seus tipos relativamente estáveis de enunciados, sendo isso que denominamos gêneros do discurso. A riqueza e a variedade dos gêneros do discurso são infinitas, pois a variedade virtual da atividade humana é inesgotável, e cada esfera dessa atividade comporta um repertório de gêneros do discurso que vai diferenciando-se e ampliando-se à medida que a própria esfera se desenvolve e fica mais complexa. 
O enunciado é visto como parte integradora e essencial na concepção dos gêneros do discurso. São os enunciados que nos movem, por isso mesmo não podem ser descontextualizados - pois não há como abstraí-los de seu contexto de realização. $O$ enunciado está em constante relação com o mundo, com nossas práticas e vivências, o que caracteriza sua configuração heterogênea e sua historicidade constitutiva. Daí, a variedade dos gêneros do discurso ser praticamente infinita (BAKHTIN, 2003), por sua função proficuamente comunicativa e dialógica. Bakhtin leva-nos ao entendimento de que o enunciado existe e pode ser significado em sua função comunicativa e social ideologicamente marcada.

Gregolin (2007a, p. 167) assinala que "a discursividade é um acontecimento que não deve perder de vista o fato de que o discurso acontece sempre no interior de uma série de outros discursos, com os quais estabelece correlações, deslocamentos, vizinhanças". Isso enfatiza que o discurso é produto de toda uma discursividade, da indispensável relação que estabelece com os outros discursos, bem como com as condições históricas de produção em que é produzido. Bakhtin (2003, p. 263) reforça que "a variedade dos gêneros do discurso é infinita", assim como a variedade da interação que envolve os sujeitos. É um todo complexo que envolve os sujeitos em processo de interação com o que enunciam e com as condições que lhes permitem enunciar.

$\mathrm{O}$ anúncio publicitário é um gênero que está inteiramente ligado às funções sociais e comunicativas da linguagem, constituindo-se em um objeto de análise de extrema relevância para o entendimento dos discursos que circulam na sociedade. Considerando que as atividades humanas são múltiplas e complexas, os gêneros do discurso tornam-se também múltiplos e complexos, principalmente, quando acompanham a dinâmica dessas atividades. Para Bakhtin (2003), não devemos, de modo algum, minimizar a extrema heterogeneidade dos gêneros discursivos e a dificuldade daí advinda de definirmos a natureza geral do enunciado. Afinal, em sua complexidade, o enunciado dá a entender sua relevância para o reconhecimento dos discursos que movem os sujeitos e suas ações cotidianas.

À luz do referencial teórico que norteia este trabalho, alguns conceitos remissivos ao anúncio publicitário são indispensáveis aos propósitos que aqui se expõem. Conforme Bezerril e Alves (2013), o anúncio publicitário é considerado um 
gênero de circulação midiática, impressa e publicitária, marcadamente ideológico. Os enunciados presentes nos anúncios "emanam de uma dada esfera social de atividade humana, a esfera da publicidade, que se constitui como campo de legitimação, regularização e significação das interações sociais que se tipificam, originando esse gênero publicístico" (Ibid., p. 335). As autoras complementam que o anúncio publicitário possui a função de "construir sentidos de credibilidade à mercadoria, divulgando um produto ou serviço com o intuito de informar e de despertar o interesse de compra/uso nos consumidores". Entretanto, esse é um conceito puramente formal e previsível, é o que já sabemos sobre o anúncio: um gênero que se propõe a vender algo.

Bezerril e Alves (Ibid., p. 329) atestam que os anúncios:

[...] são formas de enunciados concretos, aqui entendidos na perspectiva bakhtiniana, que se desenvolvem à luz de diversos valores sociais e histórico-culturais definidos, que acabam, por assim dizer, disseminando informações, raciocínios e pensamentos que permitem ao consumidor a manutenção da informação dos mais variados produtos e serviços, o aumento dos negócios, no sistema capitalista, 'a manipulação planejada da comunicação visando, pela persuasão, promover comportamentos em benefícios do anunciante que a utiliza'.

Esses comportamentos mobilizam diversas práticas sociais, não apenas referentes ao consumo do produto que se tenta vender no anúncio, mas também ao consumo de uma ideia, de um modo de existência, de novos costumes e crenças. A relevância de estudarmos o anúncio em sala de aula traduz a possibilidade de reflexões, de natureza teórica ou prática, que pode contribuir com os estudos do texto em sua complexidade ideológica e alteridade constitutiva. Observar a presença do outro no discurso pode elucidar meios de identificarmos como o dialogismo se constrói nos sentidos que mobilizam essa presença alheia no processo enunciativo. Se a linguagem é por natureza dialógica, por carregar o cruzamento das palavras do outro, necessariamente, um trabalho com os gêneros do discurso possibilita-nos repensar práticas, papéis e sentidos que contornam seu fundamento e sua existência.

Fiorin (2006, p. 21) entende que um enunciado está acabado quando suscita uma resposta no outro e isso evidencia o imbricamento dialógico que o perfaz. Nos enunciados "estão sempre presentes ecos e lembranças de outros enunciados, com que ele conta, que ele refuta, confirma completa, pressupõe e assim por diante. Todo enunciado ocupa sempre uma posição numa esfera de comunicação sobre um dado 
problema". Assim, o dialogismo é o que mobiliza o conteúdo do enunciado; nele estão inseridos a réplica de outros enunciados, seus efeitos, seus sentidos e sua ressignificação.

\section{Por uma análise dialógica do anúncio publicitário}

Se partirmos da asserção bakhtiniana de que "os enunciados e seus tipos, isto é, os gêneros discursivos, são correias de transmissão entre a história da sociedade e a história da linguagem" (BAKHTIN, 2003, p. 268), podemos entender que os gêneros publicísticos integram a vida dos sujeitos pelo diálogo que estabelecem com o seu cotidiano. Os anúncios publicitários aqui analisados estão impregnados de pontos de vista sobre a mulher e o seu lugar social. Em sua materialidade enunciativa, (re)produzem verdades sobre a mulher e lhe demarcam fronteiras por meio de uma ideia que vendem, mormente articulada aos produtos que enunciam.

$\mathrm{Na}$ esfera publicística, a mulher tem se mantido em seu lar, ela é produto de uma história que se perpetua na regularidade enunciativa de lava-louças, lava-roupas, fogões e geladeiras, que lhe são oferecidos no dia das mães, no dia internacional da mulher, entre outras datas comemorativas. Esses produtos alicerçam um mundo doméstico marcadamente feminino. No interior dessa relação, entre anúncio e consumidor, há uma rede de fidelidade e um modo de controle que asseguram sutilmente uma conduta, um modo de existência e uma história para a mulher.

Construir anúncios que divulgam eletrodomésticos ofertados à mulher é também produzir um conceito que a define em suas práticas, em sua conduta social e política. Nessa ótica, demarca-se um discurso específico para a mulher nos limites da esfera doméstica ou de um cotidiano privado que, possivelmente, justifique sua rara presença na ágora e no espaço político. Reitera-se, com isso, um pensamento dado a priori que regulariza seu silêncio e sua invisibilidade. E o que logramos desse conceito? Nada que esteja além dos estereótipos que singularizam a mulher, que limitam suas ações e particularizam sua natureza.

Bakhtin (2006, p. 123), ao defender a língua como concreta e viva, entende que esta é também lugar de propriedades dialógicas, afinal, as palavras carregam valores ideológicos que circulam entre os sujeitos em sociedade. Em sua visão, o diálogo 
institui relações que acontecem entre os interlocutores em determinado momento histórico, ele se realiza em um "tempo" e em um "local" com variações de contexto. Se o dialogismo é constitutivo da linguagem, a investigação enunciativa que se coloca em análise neste trabalho entende o anúncio publicitário como um gênero remissivo às ações comunicativas dos sujeitos, sendo, assim, puramente dialógico.

O primeiro anúncio analisado é de um produto de marca conhecida, que remete a um suposto sonho de consumo da mulher. Essa escolha se apoia no próprio valor discursivo que a propaganda carrega. São vozes discursivas que traduzem um contexto histórico, em dada época, e uma concepção do lugar da mulher na sociedade.

Maria do Rosário Gregolin (2007b), no artigo "O que quer, o que pode esta língua? Teorias linguísticas, ensino da língua e relevância social”, também analisa o mesmo anúncio publicitário que interpretamos neste artigo. A autora, um dos principais nomes da Análise do Discurso no Brasil, tem uma extensa produção investigativa sobre o discurso midiático e os efeitos de sentido que esse traduz para a sociedade enquanto resultados que espelham práticas sociais. Assim, segundo a autora, o contexto histórico que situa o devido anúncio é a década de 1977, período em que ascendem os movimentos feministas espalhados pelo mundo. O enunciado toma uma forma significativa de sentidos que dialogam com certas regularidades sociais sobre os espaços que "pertenciam e/ou pertencem” à mulher. Joan Scott (2008, p. 18), ao discutir o termo "gênero" enquanto categoria de análise histórica, assinala que "precisamos rejeitar o caráter fixo e permanente da oposição binária, precisamos de uma historicização e de uma desconstrução autêntica dos termos da diferença sexual”.

Quanto ao conteúdo temático do anúncio em questão, este perscruta sentidos que remetem à identidade da mulher e permite-nos observar o que é de praxe nos enunciados publicísticos que promovem a venda de um produto. Há um cruzamento do discurso com a potencialidade comunicativa desse tipo de enunciado em que se mobilizam imagens, desenhos, cores, para se gerar o anseio em se adquirir o produto da marca Brastemp. Então, partindo do princípio de que a sociedade é um espaço de contradições, constituído pela historicidade que define os sujeitos e lhes atribui identidade cultural, territorial, sexual, etária, situacional, entre outras, considere-se o seguinte anúncio: 
Figura 1 - Anúncio da Lava-louça Brastemp.

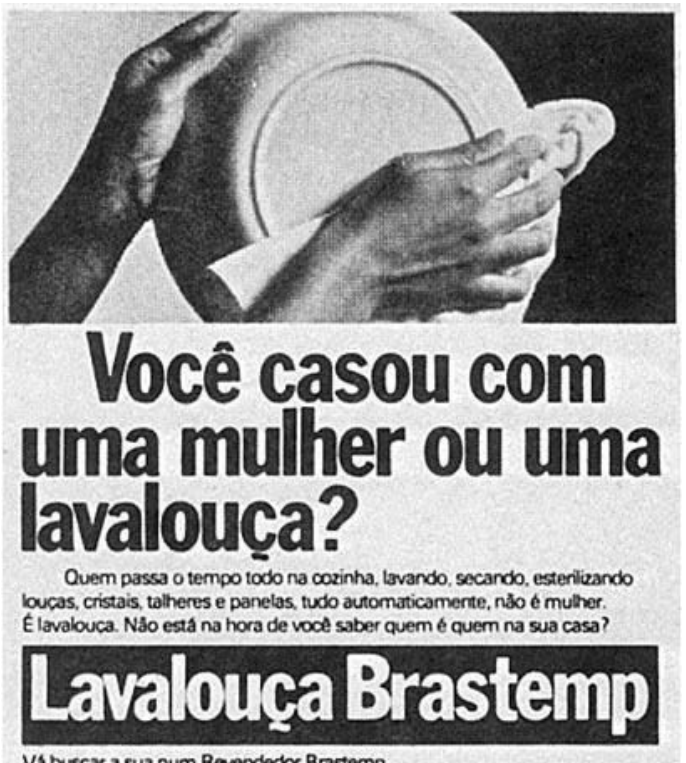

Fonte:

http://www.ccsp.com.br/anuario_pecas/integra/131/Voce-casou-com-uma-mulher-ou-u ma-lavalouca. Acesso em: 10 set. 2018.

Os enunciados que constituem esse anúncio produzem efeitos de sentido que se movimentam entre as práticas sociais cotidianas e o humor. Em outras palavras, observa-se na sequência - Você casou com uma mulher ou uma lavalouça? - um lugar identitário para a mulher que, comumente, define-a. Ela é do lar, especificamente, da cozinha, da lavanderia, das paredes que a cercam em casa, e uma de suas funções neste lar é lavar louças. O enunciado sequente apresenta os seguintes dizeres: Quem passa o tempo todo na cozinha, lavando, secando, esterilizando louças, cristais, talheres e panelas, tudo automaticamente, não é mulher. É lavalouça. Não está na hora de você saber quem é quem na sua casa? Convocando esses enunciados para uma análise mais precisa, entende-se que os sentidos são construídos em sua relação entre linguagem e sociedade. Isso necessariamente passa por uma interpelação ideológica remissiva ao lugar social da mulher na história.

Relevantemente, essa postura enunciativa sinaliza que o processo de leitura e interpretação de texto em sala de aula, especificamente, de anúncios publicitários, deve construir-se observando esse lugar discursivo de fabricação de cenários, de ideias que traduzem práticas de uma sociedade. Nesses termos, o anúncio supra-apresentado é uma instância criadora de significação que flutua entre os jogos discursivos da sociedade que 
também traduzem identidades e lugares aos seus sujeitos, ao mesmo tempo que têm a função de promover a informação do produto para a circulação e, logo, para sua venda.

O discurso que se aborda no anúncio é de ordem social relacionado ao casamento e, consequentemente, às mulheres. Pensar esse tema em sala de aula é também propor um trabalho de leitura, é desencadear discussões profícuas a respeito do tema, é produzir opiniões, reflexões. O trabalho de interpretação deve, assim, promover a leitura, segundo Orlandi (2003, p. 193), como um momento que seja crítico sobre a constituição do texto, "pois é o momento privilegiado do processo de interação verbal: aquele em que os interlocutores desencadeiam o processo de significação. É nessa interação que os interlocutores instauram o espaço da discursividade”. Não se pode, assim, trabalhar um texto em sala de aula em sua objetividade, ou buscando uma imanência no dizer. $\mathrm{O}$ trabalho deve considerar o imaginário do leitor, as permissões e as interdições de sua compreensão, do seu lugar social e cultural nesse jogo de interpretação.

O anúncio em questão teve circulação em grandes jornais no Brasil em 1977. Seu redator é Otonoiel S. Pereira, segundo as referências dadas pelo site do qual foi extraído o texto. A Brastemp é uma empresa brasileira que fabrica eletrodomésticos desde 1954, somando hoje uma das maiores exportadoras e revendedoras de seus produtos, que são: geladeira, freezer, secadora, lava-roupa e lava-louça. Os produtos Brastemp são conhecidos por facilitar o serviço doméstico. As propagandas são criativas e buscam causar um chamamento àquelas pessoas que praticam atividades domésticas. No caso do anúncio acima, temos um contexto inusitado, uma máquina de lavar louças que facilitaria a vida da suposta dona de casa. A função da empresa Brastemp é promover o produto para a venda e ao mesmo tempo manter um diálogo com seus compradores, no caso, os maridos.

A propaganda coloca o questionamento do lugar feminino no casamento, isso à época de 1977, quando se tem um contexto de transição nos costumes sociais. No período de transição do final dos anos 1970 para os anos de 1980, a mulher começa a ganhar distinção entre os homens, pois o modelo de mulher "de casa" vai perdendo suas características na ascensão dos anos 1980. Naquela mesma época, segundo os historiadores, a mulher está mais envolvida em movimentos populares que levassem à ampliação de sua participação na sociedade. 
Quando lemos: Você casou com uma mulher ou uma lavalouça?, percebemos a finalidade da empresa em instaurar um diálogo com o marido da dona de casa, na medida em que, também, instaura uma parceria com a esposa, impunha-se a "bandeira feminista" que em outras palavras diz: "Não aceite que o seu marido te trate como uma lava-louça". Por isso, a pergunta é dirigida ao esposo que trabalha e sustenta a casa, ao provedor, e tal questionamento traduz a função da esposa em seu compromisso conjugal. No texto, a mulher "perderia" um dos enquadramentos das múltiplas funções domésticas, ela é colocada como diferente da máquina, apenas a máquina de lavar louças poderia se ocupar desse trabalho. Com isso, o texto publicístico permite que o leitor se movimente em sua interpretação conduzida por valores ideologicamente ressignificados pela mídia.

Observemos, portanto, o caráter histórico do enunciado em face de sua irrestrita interação com a sociedade da época. A enunciação é o todo que se apresenta, ela não apenas traduz o enunciado, mas também uma ideia, um pensamento de uma época, uma identidade e os seus efeitos. Bakhtin (2003) observa que a enunciação deve ser compreendida como uma réplica do diálogo social. "Ela é de natureza social ideológica. Ela não existe fora de um contexto social, já que cada locutor tem um "horizonte social" (Ibid., p. 15). Na imagem da propaganda e no enunciado como um todo, entrelaçam-se marcas sociais, ideológicas e contextualizadas no texto publicitário. É a sociedade que fala, a história que diz e o anúncio que materializa ideologicamente o que todas refletem.

A análise do discurso usa mecanismos para expor os contextos históricos, considerando o fato de que "todo discurso é um índice potencial de uma agitação nas filiações sócio-históricas", um trabalho de deslocamento (PÊCHEUX, 1997, p. 56-57), bem como um trabalho de memória, de retomadas e releituras. Então, as inovações tecnológicas que passaram a povoar as cozinhas "das mulheres" possibilitaram-lhes uma "liberdade vigiada". A máquina estava lá, mas era para a mulher, quem a utilizava era a mulher. Essas inovações dialogavam obviamente com o advento do feminismo. A militância das mulheres nas ruas já começara havia algum tempo, principalmente na Europa. Elas lutavam por direitos ao voto, ao trabalho, à participação política etc.

A luta das mulheres por melhores condições de vida em sociedade remonta a tempos passados. As primeiras manifestações feministas ocorreram no século XIX, 
quando elas desafiaram a sociedade a refletir sobre sua vida rotineira de donas de casa, submissas ao homem e com direitos limitados e cerceados. Em 1977, o casamento no Brasil estava em efeito de mudança, o divórcio foi criado mostrando uma grande mudança nas dimensões da vida social que envolvia os casais. Nas palavras de Berquó e Oliveira (1992, p. 13), “estas mudanças ocasionaram, entre outras, alterações importantes no universo de expectativas das mulheres, deixando o casamento de ser a via privilegiada de concretização de projetos de vida independentes da família de origem". De certo modo, instituía-se uma bandeira, uma luta de resistência ao silenciamento que a história delegara à condição social feminina.

Embora o anúncio supra-analisado tenha sido criado na década de 1970, seus sentidos, assim como os de outros anúncios passados, são retomados nos dias atuais. A atualidade alimenta-se de uma memória discursiva que não se apaga. Os discursos são retomados, e o advento de sua volta enuncia, relembra, assegura e reforça o que é a mulher na sociedade. Isso pode sinalizar que há uma estratégia discursiva que produz o enunciado, na medida em que retoma outros já ditos, conforme vemos no anúncio a seguir.

Figura 2 - Anúncio publicitário da Fast Shop.

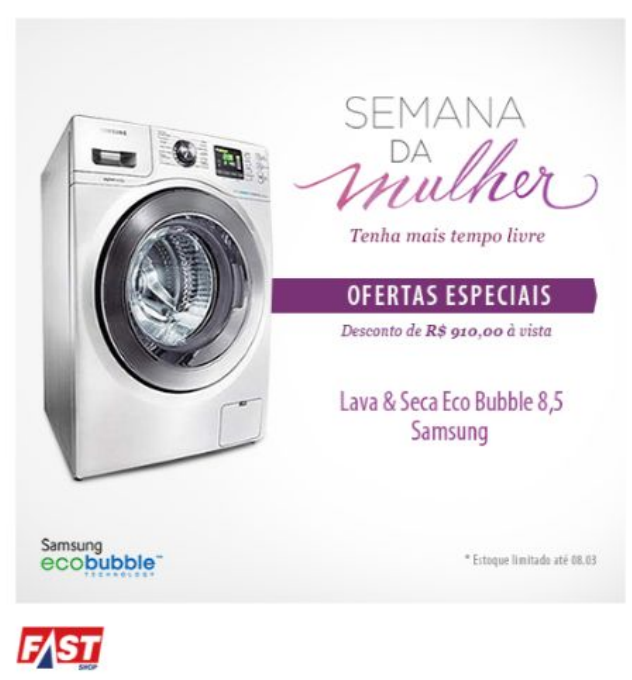

Fonte: https://www.buzzfeed.com/br/alexandreorrico/publicidade-machista. Acesso em: 15 jun. 2020. 
Temos aí uma proposta, uma sugestão de compra para a mulher. Esse anúncio Semana da mulher: tenha mais tempo livre - foi veiculado em março de 2015, na mídia nacional digital e impressa pela empresa Fast Shop, que vende computadores, televisões, home teathers, entre outros produtos. No entanto, o que se ofertou à mulher foi uma máquina de lavar e secar roupas. Ela não tem tempo livre porque as funções domésticas lhe pertencem, são de sua alçada. A máquina de lavar roupa amenizaria uma das tantas demandas domésticas. Então, como falamos da mulher, de sua identidade, das práticas que lhe são dadas, olhando para um anúncio publicitário? De que forma o enunciado acima tenta fugir do padrão, talvez sugerindo que a mulher deva trabalhar fora de casa, mas ao mesmo tempo amarrando-a à ordem do lar?

Nesses anúncios, podemos pensar em uma corporeidade de imagens amparadas por enunciados que produzem uma identidade para a mulher, pois o que se esconde por trás desses enunciados são outros que os conduzem. Não conseguimos separar a historicidade que lhes é constitutiva. Assim, podemos pensar quais são os procedimentos composicionais e enunciativos que esses anúncios organizam em seus discursos para conquistar ou reconquistar a sua suposta cliente. Pierre Achard (2007, p. 17), ao discutir o papel da memória, observa que um texto dado trabalha através de sua circulação social, "o que supõe que sua estruturação é uma questão social, e que ela se diferencia seguindo uma diferenciação das memórias e uma diferenciação das produções de sentido a partir das restrições de uma forma única”. A produção da publicidade repousa em uma dada instabilidade, entre o esquecimento e a repetição de uma história que assegura à mulher um espaço socialmente determinado. Para Bakhtin (2006, p. 144), "pode ser que o discurso de outrem seja recebido como um único bloco de comportamento social, como uma tomada de posição inanalisável do falante”. Os sentidos desses enunciados, por outro lado, podem também dar a inferir que se reconhece uma nova posição para a mulher, de mudança, de liberdade, talvez, de inovação. Mas, o olhar que aqui se lança é sobre a não transparência do dizer, é sobre o que não é dado a se perceber facilmente.

Gregolin (2007a, p. 163) assinala que essas retomadas "são procedimentos discursivos que trabalham a memória e fazem esses enunciados integrarem-se a redes de outras formulações e constituírem outros trajetos de sentidos”. A máquina é para a mulher, ou seja, ela diz que embora o tempo mude, os anos passem e a inovação 
aconteça, o seu lugar é o mesmo de antes e de sempre, as suas funções domésticas são as mesmas de outrora e acontecem sempre entre a cozinha e a lavanderia.

Esses enunciados, pela insistente recorrência e repetibilidade com que voltam à cena midiática e publicitária, constituem também maneiras de se definir a mulher e de levá-la a se reconhecer em seu lugar social, identitário etc. Segundo Lima (2018), conforme os enunciados sobre a mulher vão sendo produzidos, outros efeitos de sentido, em concomitância, são mantidos ou deslocados. Para a autora, esses enunciados, apesar de obedecerem a certas regularidades, não fogem ao compromisso de denunciar os posicionamentos femininos nos discursos e as correlações e transformações no processo de construção da identidade da mulher (LIMA, 2018, p. 159). Há uma historicidade rememorada nessa construção. Por isso, podemos depreender que as relações dialógicas que engendram os sujeitos nesses enunciados analisados são demasiadamente complexas, pois também lhes atribuem um modo de existência e, em seu esteio, relegam-lhes um lugar fixo na sociedade.

Trabalhar com anúncios publicitários na sala de aula pode ser uma motivação para entendermos o processo de interação que mobilizam os textos e suas diferenças na sociedade. É um convite a enxergar questões que não são dadas sob ângulos tão conhecidos, mas que nos fazem repensar as práticas e os papéis dos sujeitos engendrados em seus enunciados, entre cores, formatos e produtos a se consumirem.

A estrutura composicional desses enunciados mostra os objetos à venda: a máquina de lavar louça e a máquina de lavar roupa. Compreendemos que há um movimento entre eles, entre um passado e um presente, entre a louça e a roupa, entre a mulher de antes e a mulher de agora, entre o cinza e o colorido, respectivamente, no anúncio de 1970 e o de 2015 que, em certa medida, asseguram o lugar da mulher na mídia. É o discurso midiático que parte de um já dito e que dá base a um dizível.

Os modos como são enunciados definem as formas de discursividade que nos chegam diariamente por meio dos aparelhos midiáticos. São modos de produção de identidades que cotidianamente asseguram uma fixidez que define os sujeitos em sociedade e os seus modos de existência. Afinal, "as mulheres são imaginadas, representadas, em vez de serem descritas ou contadas" (PERROT, 2007, p. 17). Nas palavras de Barthes (1993, p. 7 apud LIMA, 2018, p. 169), por meio de falsas evidências, "a mídia mascara continuamente uma realidade, confundindo, nos relatos da 
atualidade, natureza e história, e atribuindo, por meio de um 'abuso ideológico', certa obviedade natural àquilo que é puramente histórico". A identidade da mulher nesses anúncios está presa à teia de uma memória agenciada pelo discurso midiático.

\section{Considerações finais}

Este trabalho teve como objetivo investigar um anúncio publicitário, segundo os fundamentos propostos por Mikhail Bakhtin (2003) e por alguns estudiosos da teoria discursiva, com vistas a uma possível contribuição para os estudos dos gêneros do discurso. Observamos, por meio da análise e visão de alguns autores, as regularidades estabelecidas nos anúncios, principalmente, quando mobilizam conteúdos temáticos relacionados ao lugar da mulher na sociedade. Ou seja, eles dialogam com as práticas sociais e com os seus valores como se estes lhes fossem intrínsecos e naturais, o que sinaliza uma tentativa de regulação social para os sujeitos. Observamos, assim, o sujeito tomado como lugar de práticas discursivas que servem de campo para a sua construção e existência no discurso (LIMA, 2018, p. 172).

Bakhtin (2003) induz-nos ao entendimento de que as relações dialógicas, em sua multiplicidade, podem ser contratuais ou polêmicas, de divergência ou de convergência, de aceitação ou de recusa, de acordo ou desacordo, de entendimento ou de desinteligência, de avença ou de desavença, de conciliação ou de luta, de concerto ou de desconcerto. Assim, “a relação com o sentido é sempre dialógica. A própria compreensão já é dialógica" (BAKHTIN, 2003, p. 327). O dialogismo pode ser entendido como uma dinâmica entre discursos, constituído nas relações tensas que mobilizam as práticas sociais, bem como as relações de poder que se instauram entre os sujeitos. Observamos, portanto, que esse é um viés interessante de reflexão a ser levado à discussão, sempre observando como os sentidos são permeados pelas relações de poder e de diferenças que traduzem, definem e identificam os sujeitos em sociedade.

As regularidades que contornam essas relações de poder nos espaços sociais, principalmente em suas demarcações de diferenças entre o que é do homem e o que é da mulher, permitem que os discursos individualizem os sujeitos. Falar de mulher na mídia é diferente, é singular, é também uma tentativa de se compreender sua identidade, sua natureza, ou, talvez, uma possibilidade de dar-lhe uma natureza, uma identidade fixa, 
ainda, circunscrita aos espaços domésticos e às fronteiras que mantêm a mulher resguardada, obviamente, sob o jugo do discurso midiático-publicitário.

\section{Referências}

ACHARD, Pierre. Memória e produção discursiva do sentido. In: ACHARD, Pierre et al. Papel da memória. Tradução de José Horta Nunes. Campinas: Pontes, 2007.

BAKHTIN, Mikhail; VOLOCHÍNOV, Valetin Nikolaevich. Marxismo e filosofia da linguagem. Tradução de Michel Lahud e Yara Frateschi Vieira. 10ª ed. São Paulo: Huditec, 2006.

BAKHTIN, Mikhail Mikhailovitch. Estética da criação verbal. Tradução de Paulo Bezerra. $4^{\mathrm{a}}$ ed. São Paulo: Martins Fontes, 2003.

BEZERRIL, Gianka Salustiano; ALVES, Maria da Penha Casado. Aspectos da dimensão verbal do gênero anúncio publicitário impresso direcionado ao público masculino. Revista do GELNE, Natal, vol. 15, Número Especial, p. 327-352. 2013. Disponível em: https://periodicos.ufrn.br. Acesso em: 7 set. 2019.

BERQUÓ, Elza; OLIVEIRA, Maria Coleta F. A. de. Casamento em tempos de crise. Revista Brasileira de Estudos Populacionais, Campinas, vol. 9, n. 2, 1992.

FIORIN, José Luiz. Introdução ao pensamento de Bakhtin. São Paulo: Editora Ática. 2006.

GREGOLIN, Maria do Rosário. Formação discursiva, redes de memórias e trajetos sociais de sentido: mídia e produção de identidade. In: BARONAS, Roberto Leiser. Análise do discurso: apontamentos para uma história da noção-conceito de formação discursiva. São Carlos: Pedro \& João Editores, 2007a.

O que quer, o que pode esta língua? Teorias linguísticas, ensino da língua e relevância social. In. CORREIA, Djane Antonucci (Org.). A relevância social da linguística: linguagem, teoria e ensino. São Paulo/Ponta Grossa: Parábola/Editora da UEPG, 2007b, p. 51-77.

LIMA, Fernanda Fernandes Pimenta de Almeida. Deslocamentos de politização no discurso: um olhar semiótico sobre a mulher na política. Línguas e Instrumentos Linguísticos, n. 42, jul.-dez., 2018. Campinas: Unicamp, 2018. p. 155-174. Disponível em:

http://www.revistalinguas.com/edicao42/artigo 7.pdf.

ORLANDI, Eni. Discurso e texto: formação e circulação dos sentidos. Campinas: Pontes, 2003.

PÊCHEUX, Michel. A análise do discurso: três épocas. In: GADET, François; HACK, T.

(Org.). Por uma análise automática do discurso: uma introdução à obra de Michel Pêcheux. Campinas: Editora da Unicamp, 1997. 
PERROT, Michelle. Minha história das mulheres. Tradução de Ângela M. S. Corrêa. São Paulo: Contexto, 2007.

SCOTT, Joan. Gênero: uma categoria útil para análise histórica. 2008. Disponível em: https://edisciplinas.usp.br/pluginfile.php/185058/mod_resource/content $/ 2 / \mathrm{G} \% \mathrm{C} 3 \% \mathrm{AAn}$ ero-Joan\%20Scott.pdf. Acesso em: 2 jul. 2019. 